Juliette Vazard

Epistemic Anxiety, Adaptive Cognition, and Obsessive-Compulsive Disorder

Abstract: Epistemic Anxiety, Adaptive Cognition, and Obsessive-Compulsive
Disorder

Emotions might contribute to our being rational cognitive agents. Anxiety - and more specifically epistemic anxiety - provides an especially interesting case study into the role of emotion for adaptive cognition. In this paper, I aim at clarifying the epistemic contribution of anxiety, and the role that ill-calibrated anxiety might play in maladaptive epistemic activities which can be observed in psychopathology. In particular, I argue that this emotion contributes to our ability to adapt our cognitive efforts to how we represent the practical factors relevant to the task at hand, by signaling the need for increased cognitive processing and evidence gathering in highstakes situations. I hypothesize that dysfunctional or ill-calibrated epistemic anxiety might play an important role in the motivation driving persons with obsessivecompulsive disorder (OCD) to invest high amounts of cognitive resources into the resolution of apparently simple and innocuous questions. As I argue, OCD might be conceived as a case in which epistemic anxiety is inappropriately elicited, representing these as high-stakes questions, and inadequately signaling a need for cognition. In this paper, I thus make use of the concept of (epistemic) anxiety as developed in the philosophy of emotion and in epistemology, to propose an account of the role of anxiety in the pathological doubt that is central to obsessive-compulsive disorder.

Keywords: Epistemic Anxiety, Epistemic Emotions, Adaptive Cognition, Obsessive-Compulsive Disorder, Reasonable Doubt.

\title{
Introduction
}

Being epistemically virtuous requires, among other things, wellcalibrated affective dispositions. As Adam Morton (2010, p. 388) puts it: "in order to acquire beliefs successfully people need to be careful, curious, imaginative, and responsible, all at the right moments and to the right degree”.

Emotions might not only contribute to our being virtuous agents, but also rational cognitive agents. Adaptive cognition refers to the idea that agents adapt their cognitive efforts to how they represent the practical factors relevant to the task at hand. For instance, agents naturally invest more cognitive effort into resolving questions that are deemed important, with regard to their practical implications. Since we have only so much effort available to 
allocate to all our endeavors, regulating the deployment of cognitive activities in a way which serves our practical interests is crucial. Ecological rationality demands that real-world concerns such as practical stakes impact on the amount of cognitive resources that we should be willing to invest in the resolution of a given question. Failing to devote available cognitive resources to an important cognitive task can be profoundly detrimental. Likewise, devoting excessive cognitive resources to a task is irrational and maladaptive (Gigerenzer 2008). Emotions certainly play a crucial role in our ability to strike a balance between the costs in time and cognitive resources that investigation involves, and the benefits of improving one's epistemic position (de Sousa 1979, 1987; Gigerenzer, Todd 1999).

Anxiety - and more specifically epistemic anxiety - provides an especially interesting case study into the role of emotions for adaptive cognition. In this paper, I aim at clarifying the epistemic contribution of anxiety, and the role that ill-calibrated anxiety might play in maladaptive epistemic activities which can be observed in psychopathology. In particular, I argue that this emotion contributes to our ability to adapt our cognitive activities to practical factors relevant to the task, by signaling the need for increased cognitive processing and evidence gathering in high-stakes situations. If this is so, then we have an emotion which helps us quickly identify those questions which are worth extra cognitive effort, and thereby allows us to allocate cognitive resources in a way which serves our practical interests.

I further hypothesize that dysfunctional or ill-calibrated epistemic anxiety might play an important role in the motivation driving persons with obsessive-compulsive disorder (OCD) to invest important amounts of cognitive resources into the resolution of apparently simple and innocuous questions. In OCD, persistent doubting, uncertainty and indecisiveness prevent the individual from carrying out daily activities. Doubt, however, is an emotional reaction, and perhaps one that can best be captured in terms of epistemic anxiety. OCD might thus be conceived as a case in which epistemic anxiety is inappropriately elicited, representing innocuous questions as high-stakes, and inadequately signaling a need for cognition.

When the emotion does not reliably represent the stakes involved in resolving a given question, this is likely to result in maladaptive epistemic practices. In the contrary, when it is well-calibrated, anxiety is part of an adaptive mechanism which helps us efficiently distribute cognitive effort. As such, anxiety presents a good example of the way in which emotions support adaptive cognition. I thus make use of the concept of epistemic anxiety as developed in the philosophy of emotion and in epistemology, to propose an account of the role of anxiety in the pathological doubt that is central to obsessive-compulsive disorder. 
In what follows, I first clarify the notion of adaptive cognition and the type of mechanisms which contribute to our ability to adjust our cognitive processes to practical factors. I then present the thesis according to which emotions make certain features of situations or arguments more salient, thereby reducing the amount of information to consider in order for us to make decisions and act. I present anxiety as a case study and propose to focus my inquiry particularly on emotional episodes of epistemic anxiety. I then turn to presenting OCD, and I suggest that one of its central features persistent doubt - can be understood as an excess of epistemic anxiety. I further specify that epistemic anxiety motivates sustained epistemic behaviors by representing practical stakes as high and consequently signaling the need for elevated evidence requirements and increased cognitive processing.

\section{Adaptive Cognition}

What are the mechanisms which support our ability to efficiently allocate our cognitive resources? On what basis do we automatically spend more time and effort resolving certain questions? How do we set the threshold of evidence and for when an investigation should be terminated?

There is a broad consensus on the idea that variations in cognitive effort are generally adaptive: we typically invest more or less resources in forming beliefs depending on the expected rewards for accuracy or costs for inaccuracy. We can refer to adaptive cognition as the "broad label for the idea that agents adapt their cognitive efforts to how they represent the practical factors relevant to the task at hand" (Gerken 2017, p. 199). According to the adaptive toolbox model (Gigerenzer, Todd 1999; Gigerenzer 2008), humans possess an adaptive toolbox, consisting of "cognitive mechanisms that evolution has built into the human mind for specific domains of inference and reasoning, including fast and frugal heuristics" (Gigerenzer, Todd 1999, p. 30). Some of these mechanisms hence function to help us adjust our use of cognitive processes to "real-world requirements" and to the practical factors we face.

For instance, it has been proposed that the need for closure and the need for cognition correspond to motivational tendencies also called "epistemic needs". The need for closure and the need for cognition are thought to motivate us to either stop or continue an inquiry, by representing the costs and benefits of acquiring a better epistemic position, given relevant factors of the practical context (Kruglanski 1990; Roets et al. 2015). The need for cognition can thus undermine and postpone the need for closing an inquiry, when the benefits of continuing the search for information are salient. Particularly, perceived high stakes lead to a disposition on the part of 
the agent to improve their epistemic position with regard to $p$ (Mayseless, Kruglanski 1987).

The ability to invest more or less cognitive efforts in resolving a question, based on practical factors such as stakes, is part of being a rational cognitive agent. "Ecological rationality" indeed requires that real-world concerns impact the reasoning that precedes decision-making (Gigerenzer, Todd 1999). Failing to devote available cognitive resources to an important cognitive task can be profoundly detrimental. Likewise, devoting excessive cognitive resources to a task is irrational and maladaptive (Gigerenzer 2008).

As we shall now see, emotions certainly play a crucial role in our ability to strike a balance between the costs in time and cognitive resources that investigation involves, and the benefits of improving one's epistemic position.

\section{Emotions and Epistemic Rationality: striking a compromise}

There are important cognitive functions which humans cannot perform successfully without relying on the efficiency-enhancing quality of emotions. De Sousa (1987) and Amélie Rorty (1980) propose that emotions provide us with a framework for cognition, by making certain features of situations or arguments more prominent, giving them a weight that they would otherwise lack. In an influential thesis de Sousa has argued that "emotions are determinate patterns of salience among objects of attention, lines of inquiry, and inferential strategies" (de Sousa 1979, p. 50).

It is suggested that emotions act as a source of salience and relevance, helping agents with limited resources to reduce the number of actions and consequences that they should consider if they ever want to reach a decision and act. In other words, we need emotions so as not to be paralyzed in our decision-making by the overwhelming volume of potentially relevant knowledge and information. ${ }^{1}$ This directive power which emotions exert over cognitive processes places us in a more favorable epistemic position than the one which reasoning alone could grant us (Robinson 2005). ${ }^{2}$

It seems quite clear that if we were to guide belief-formation solely on the basis of reflective deliberation, the questioning and search for infor-

${ }^{1}$ Let me emphasize that the claim is not that the only way to narrow down information for an inquiry is via emotions. Cold deliberation can be sufficient and possible in certain circumstances (in which we have the time and all the relevant information at hand). However, as finite creatures with limited resources, the type of directive power which emotion exerts over our attentional focus plays a crucial role in our ability to deal with our environment, and particularly in situations where factors such as urgency and high stakes are involved.

${ }^{2}$ While emotions do not necessarily make our beliefs more justified or more conducive to knowledge, by helping us to focus on the relevant options they enable conditions for knowledge. 
mation could go on indefinitely. As Gigerenzer and Todd (1999, p. 31) note "emotions can also function as heuristic principles for guiding and stopping information search". Our condition as limited creatures often requires us to strike a balance between maximizing belief accuracy and "fast and frugal" decision-making. Emotions might contribute to our ability to do this by rendering us sensitive to practical factors impacting information search, such as stakes and urgency.

In what follows, I will introduce the case of anxiety as an example of an emotional process which supports our capacity to be rational cognitive agents by directing cognitive activities and guiding the search for information in inquiry.

\section{Introducing anxiety}

Anxiety indeed provides an especially interesting case study into the role of emotion for adaptive cognition. In what follows, I will argue with Nagel (2010) that this emotion supports our ability to adapt our cognitive activities to practical factors relevant to the task, by helping us to quickly identify high-stakes questions and invest greater cognitive efforts in their resolution. But first, let us now provide a broad introduction of anxiety and on the diverse and changing views regarding its potential functions.

Folk conceptions of anxiety tend to view it in negative terms: it is said to be an inherently unpleasant, impairing affective state, which can paralyze us in moments in which we would critically need to take action. In philosophy, anxiety, and perhaps negative emotions more generally, have long been viewed as impairments to the pursuit of a virtuous life, and research has tended to focus on cases where it manifests in debilitating ways. Traditionally, characteristic of the virtuous agent is "serenity" and "harmony" of beliefs within "a tranquil mind" (Kant 1797/1996; Annas 1993, 2011; Hursthouse 1999; McDowell 1998). The idea that emotions "capture and consume" our attention in a way that can have "a deleterious effect on our epistemic standing" is often emphasized in philosophical treatments of emotion (Brady 2013, p. 159).

However, as philosophers are slowly uncovering the value and contribution of emotional states in key human achievements like knowledge, virtue, and well-being, the idea that a negative emotion such as anxiety would be intrinsically useless and even detrimental is becoming less and less convincing. Indeed, psychologists have long acknowledged the role of anxiety for human performance. David Barlow, clinical psychologist and founder of the Center for Anxiety and Related Disorders at Boston University argues: 
we have known for almost 100 years that our physical and intellectual performance is driven and enhanced by the experience of anxiety, at least up to a point. In 1908, Yerkes and Dodson demonstrated this in the laboratory by showing that the performance of animals on a simple task was better if they were made "moderately anxious" than if they were experiencing no anxiety at all. Since that time, similar observations have been made concerning human performance in a wide variety of situations and contexts. Without anxiety, little would be accomplished. The performance of athletes, entertainers, executives, artisans, and students would suffer; creativity would diminish (Barlow 2001, p. 9).

While anxiety is unpleasant and can impact well-being if it is felt to an intense degree or over a long period of time, moderate anxiety is generally felt for good reasons and in a way that can prove beneficial, both in terms of the accomplishments it allows, and in terms of the protection it grants through making us aware of potential dangers. So what is anxiety? The DSM-IV proposes that anxiety corresponds to "apprehension, tension or uneasiness that stems from the anticipation of danger" (American Psychiatric Association 1994, p. 392). Anxiety can be conceptualized, functionally speaking, as an adaptive warning system that directs attention onto possible sources of danger and motivates coping behavior, thereby allowing for a higher level of functioning in potentially threatening environments (HoehnSaric, McLeod 2000).

Like other emotional phenomena, anxiety plays a motivational role in preparing us to act in response to the type of evaluation it makes. What sort of evaluation does anxiety involve, and what sort of responses does it prompt in individuals? As David Barlow (2001, p. 64) suggests: "If one were to put anxiety into words, one might say, 'That terrible event could happen again, and I might not be able to deal with it, but I've got to be ready to try". This suggests that anxiety involves an evaluation of one's ability to cope with a (possible) threat, as well as a readiness to face it. Given the functional characteristics of anxiety which we have highlighted, the associated phenomenological characteristics might be described as follows.

In phenomenological terms, anxiety seems to translate into 1) tension, unease and concern, as well as 2) vigilance, alertness, and readiness. We propose to understand the first set of feelings as being linked to the appraisal of our lack of information - or "epistemic gap", and the second set of feelings as arising in reaction to or as a consequence of this appraisal, as a manner of defense.

In anxiety, it is first our lack of information - our ignorance - which makes us unprepared for coping with what the future may hold. Given that the content of anxiety also includes an epistemic gap, or the idea that the subject is missing some information on the potential threat (such as the form it might take, its magnitude, the moment it might arise, or one's own 
abilities to cope with it), anxiety is first experienced as a state of vulnerability, which creates tension, unease and concern. ${ }^{3}$

In reaction to this, anxiety prompts caution and focuses attention. Since we lack information about the dangers we may encounter, when they might arise, what kind of defense they might require from us, etc., we resort to a mode of vigilance and alertness, which means that we prepare ourselves to respond quickly to all sorts of different dangers which may arise.

As we shall now see, this state of vigilance and readiness can be experienced in anticipation of specific events (e.g. a flight), or with a certain consistency over time and across situations. Anxiety can be conceived as an emotion, a mood, or an emotional disposition, and I shall now clarify the kind of anxiety I will be interested in here.

First of all, an important distinction with regard to anxiety is between trait and state anxiety. Trait anxiety refers to an individual's stable tendency to experience anxiety. It can also be viewed as an emotional disposition, which corresponds to a tendency to experience a particular family of emotions (Deonna, Teroni 2012). For instance, the anxious person will supposedly have a greater than normal tendency to feel anxiety, fear, and apprehension, and to be alert and on the lookout for potential threat, with some consistency across situations and over time.

State anxiety refers to a relatively short-lived episode of anxiety. Emotional states can be defined as affective responses involving bodily sensations or feelings that are directed towards specific states of affairs, objects or events (which can be occurring, as well as imagined, or remembered). When anxiety refers to an emotion, it is therefore a relatively short-term episode elicited in response to (or in anticipation of) a specific aspect of our environment (an upcoming meeting, an exam, etc.) ${ }^{4}$

I shall make clear to the reader that in this paper I am interested in discussing specific cases of anxiety in which it is an emotion, i.e. a relatively short-lived state in which a specific object or event is evaluated as potentially threatening. ${ }^{5}$ In the following argument, I will therefore be focusing on

3 These phenomenological characteristics of anxiety might be salient only in cases of intense and pathological anxiety. There might be cases of unconscious anxiety, which is phenomenologically silent and manifests itself only through its functional characteristics. Hence, the phenomenological characteristics described here might not be essential to all cases of anxiety. In an effort to propose a unified account of anxiety, applicable to the understanding of both typical and pathological cases, I do not want to exclude that anxiety plays the function I argue it does, even when it is not felt.

${ }^{4}$ This being said, one might be anxious without knowing why or being conscious of the object of one's affective state.

${ }^{5}$ Like emotions, moods are associated with bodily sensations and feelings (they have a specific phenomenology), but they typically last for longer. Moreover, and this might be the 
anxiety as an occurrent emotional episode, rather than a mood or a disposition, because I wish to examine the role played by this affective state when it is directed at a specific proposition or object.

\section{Formal object of anxiety}

As I intend to be speaking of anxiety as an emotion, i.e. an intentional state characterized by a specific evaluative stance, I ought to define the type of evaluation that is at play in anxiety. Which kind of evaluative property does anxiety track and respond to? In other words, what is the formal object of anxiety?

Anxiety has often been defined with regard to the emotion of fear. However, while fear is considered a basic, fundamental, discrete emotion which has a clear functional value in the evolutionary sense, anxiety has been considered both different from discrete emotions and rather vague and imprecise (Barlow 2001). A difference between anxiety and fear, it has been suggested, could be that fear is a response to a specific source of danger, while anxiety is objectless (Öhman 1993).

Rather than being objectless, the emotion of anxiety is felt with regard to a future threat, or one which is surrounded by uncertainty. It is therefore sensitive to subtle cues in our environment, rather than readily perceivable dangers. Kurth (2015, p. 5) locates the formal object of anxiety in "problematic uncertainty". He proposes that anxiety is a sort of evaluation of certain features of our environment as revealing that our ignorance about certain matters might make us unprepared in the face of a possible threat. This uncertainty needs to be addressed, because it potentially involves a prospect that is appraised as harmful for the individual. According to Kurth, anxiety is a form of evaluative awareness of a situation as involving "a threat or danger whose potential is unpredictable, uncontrollable, or otherwise open to question" (Kurth 2015, p. 5). Hence, according to this definition of

main distinction between the two, while emotions have intentional objects, moods are not generally thought of as being elicited in response to specific objects or events. Anxiety has sometimes been viewed as a mood, rather than an emotion. For instance, David Barlow defines "anxious apprehension" (in his view a more precise term for anxiety) as "a future-oriented mood state in which one is ready or prepared to attempt to cope with upcoming negative events" (Barlow 2001, p. 64). In a somewhat similar manner, Price proposes that moods regard the occurrence of a situation of a certain type (i.e. an offense, a threat, etc.) and have the function of preparing the subject to this specific type of events: "an irritable or apprehensive subject will be on the lookout for a certain kind of situation; and, should it arise, will respond more quickly and more robustly" (Price 2006, p. 57). 
anxiety, the uncertainty surrounding the threat is what distinguishes the evaluative content characteristic of anxiety from the one characteristic of fear.

The suggestion to define "problematic uncertainty" as the formal object of anxiety fits well with Barlow's view of the kind of evaluation involved in anxiety as signaling the possibility of an upcoming negative event. However, one might ask: is uncertainty a necessary feature of anxiety? It seems that we sometimes report being anxious about a specific event where we already know much of the relevant detail. For instance, we might be anxious about giving a talk to an audience because we have a stutter and we know (from experience) that some members of the audience will laugh and others will feel uncomfortable, or we might feel anxious about our ex bringing their new partner to a party. We met this new partner previously and they made us feel quite inadequate and sad about the break up, and sure enough this is what they will do again at the party. In these cases, it looks like we are anxious about a known and predictable series of events. ${ }^{6}$ If we accept these as cases of anxiety, it looks like this undermines the relevance of Kurth's "uncertainty" feature of the formal object of anxiety.

We can indeed call these instances of anxiety: these are situations in which we think "That terrible event could happen again, and I might not be able to deal with it, but I've got to be ready to try". However, the fact that these terrible events (people laughing at me, and my ex's girlfriend making me feel inadequate) have happened in the past does not allow me to predict that they will happen again today. My past experiences are just enough to create an apprehension which will help me prepare in the event that such similar threats should arise again. All I know is that these are situations (the party, the talk) in which there is a possibility (no matter how likely I evaluate it to be) that such terrible events occur. For instance, I do not know quite how bad things might turn out: my ex and their new partner might even voluntarily humiliate me in front of my new date by pushing me into the swimming pool all dressed. These are risky situations, and the fact that I cannot predict exactly what will happen and how bad this might make me feel is what justifies my feeling anxious, because the object of my anxiety is not a general event, but the more fine-grained features of that event. In fact, I really wish I knew exactly how events would unfold, and if I were in such a state (imagine a Groundhog Day scenario), I would supposedly feel fear (or resignation), rather than anxiety.

This way of characterizing the relation of anxiety to uncertainty might raise some further concerns. There are certain situations - for instance taking a plane - about which one might feel anxious while there is little uncer-

\footnotetext{
${ }^{6} \mathrm{I}$ want to thank an anonymous reviewer for bringing this point to my attention.
} 
tainty about whether the dreaded event will happen: I am not intending to change my plans, so the probability that I will indeed end up flying is very high. In other words, in certain situations, it looks like I am anxious precisely because I know how events will unfold. I see two ways of answering to this concern.

The first way is to insist on the idea that what I am anxious about is not an event such as "taking the plane", but the (many) threatening possibilities that this event contains. All I know is that by taking the plane I expose myself to the possibility of many dreadful scenarios arising. Through my anxiety, I evaluate "taking the plane" as a type of situation in which threatening possible scenarios are more likely than usual to occur. Hence, similarly to what I have proposed above, the uncertainty concerns the fine-grained features of the event, and the event itself is only evaluated as carrying possibilities of threat.

A second way of answering to this concern is by proposing that, in these situations, the uncertainty involved in my taking the plane (or the elevator) might not so much concern the potential threatening scenarios which may unfold, but my own ability to face them. In other terms, I might be anxious because I do not know whether I will be able to cope with a particular situation (such as heavy turbulences). The uncertainty is here primarily about my own coping potential, not about future events. Here are two ways in which uncertainty can be said to elicit an anxious response. This being said, the idea that uncertainty is a constitutive element of anxiety leaves open the possibility of describing cases of anxiety in which this uncertainty is hidden.

Now that we have a better idea of what anxiety is about, it still seems to apply to a large range of different objects, and I shall now specify the kind of objects I am interested in.

\section{Kinds of Anxiety}

Anxiety acts as a signal that the situation we are in contains an uncertainty which we should address. It can occur within different contexts and domains of human life, and we can accordingly distinguish different kinds of anxiety.

For instance, social anxiety can be defined as an emotional response to an aspect of a social interaction involving a problematic uncertainty (have I said something inappropriate? Have I been rude?). In this context, the uncertainty regards whether or not I might have fallen short of social norms, which is surely something that I should address.

Likewise, moral anxiety can be understood as a response to a problematic uncertainty about the correctness of a moral decision I am contemplating or have made (Kurth 2015). And thus, to feel morally anxious is to view 
one's moral decision as possibly open to moral objection, which is again something that I should address.

A third kind of anxiety is directed at epistemic uncertainties. Episodes of epistemic anxiety are emotions directed at some of our beliefs, or a proposition we are considering for belief (the bank will be open on Saturday morning/the next flight for New York will leave in an hour) which is evaluated as poorly supported by evidence, where this is viewed as potentially harmful. The emotion then raises a doubt on whether it is safe for us to form (or maintain) the corresponding belief. I will later argue that epistemic anxiety acts as a general motivation to invest greater efforts and collect more evidence in contexts that are evaluated as bearing important practical implications for us. We might consider that this is the most fundamental kind of anxiety, since both moral and social anxiety seem to involve subjective uncertainty and feelings of epistemic anxiety.

In all three cases, anxiety is directed at a specific uncertainty which is made salient, appraised as problematic, and calling for resolution. In this paper, I am specifically interested in the third kind of anxiety: epistemic anxiety, and in its contributions to adaptive cognition. The reason why I want to focus on this kind of anxiety, is that I believe it might be central to understanding important aspects of obsessive-compulsive disorder (OCD), to which I now turn.

\section{Obsessive-Compulsive Disorder (OCD)}

In the case of emotions like fear and anxiety, emotional disorder can take many different forms. Phobias, panic attacks, post-traumatic stress disorder (PTSD), pathological worry, and OCD, are all labels for types of disordered fear and anxiety. While the DSM-IV (1994) classifies OCD as an anxiety disorder, the DSM-5 (2013) creates a separate category for OCD and related disorders (such as hoarding, skin-picking, and bodydysmorphic disorder). However, anxiety is recognized to play an important role in this disorder, which involves "marked anxiety or distress" as a diagnostic criteria, and compulsions that are aimed at "preventing or reducing anxiety" (DSM-5). Moreover, up to $76 \%$ of patients with OCD are thought to suffer from either generalized anxiety disorder, panic disorder, phobias, or social anxiety disorder (Diniz et al. 2012). Some clinicians even claim that negative emotions like anxiety play a major causal role in the disorder. David Barlow for instance argues that "obsessions and compulsions represent situations in which strong anxiety and/or other negative emotions (e.g., guilt or disgust) have overtaken rational thinking and behavior" (Barlow 2001, p. 522). 
The disorder most often implies two elements: obsessions "which are intrusive, unwanted thoughts, ideas, images, or impulses" and compulsions, which are "behavioural or mental rituals according to specified 'rules' or in response to obsessions" (Abramowitz, McKay, Taylor 2008, p. 5). The three main themes of obsessions are aggressive (such as thoughts of harming children or relatives), sexual (such as fears that one will engage in inappropriate acts with inappropriate partners), or blasphemous thoughts (such as the fear of making sacrilegious gestures in a holy place), and other themes such as contamination are also frequent. The most common compulsive acts include repetitive checking (of locks, appliances, light, etc.), washing, counting, the need for reassurance seeking or unnecessary confessions, and repetitive attempts to attain symmetry (Attiullah, Eisen, Rasmussen 2000).

Even if they do not develop the debilitating disorder that OCD is, a vast majority of individuals in the general population experiences intrusive thoughts and neutralizing activities on a daily basis (Rachman, de Silva 1978; Salkovskis, Harrison 1984). Unwanted, intrusive thoughts are not exclusive to OCD, and they only represent the raw material of obsessions. According to Rachman (2003, p. 4), it is not the thoughts in themselves, but the fact that individuals interpret them as revealing an "immoral, evil dangerous, insane" character, which generates distress and gives rise to attempts to put matters right, neutralize or suppress them, which in turn will contribute to their recurrence. According to most psychological accounts of OCD, compulsions are then performed in order to control thoughts and reduce the discomfort caused by the appraisal of obsessions as immoral and/or dangerous (Salkovskis 1985, 1999; Rachman 1993; Bolton, Hill 1996).

\section{Unreasonable doubt as inappropriate anxiety}

Understanding epistemic anxiety might be important to understanding OCD, because the attitude that is recognized as most characteristic of the disorder is that of doubt and uncertainty. Patients are not afraid of what is, but of what "might be".

OCD was once referred to as "la folie du doute" (the "questioning mania"), highlighting the central role of indecision and doubt in its symptomatology (Janet 1903). Nowadays, doubt is still considered an important feature of the disorder, and has been linked to the inability to "experience a sense of conviction" (Shapiro 1965), put closure on experience (Reed 1985), or generate the normal "feeling of knowing" (Szechtman, Woody 2004). Individuals with OCD exhibit indecisiveness which translates in their difficulty to make even simple decisions (Tolin et al. 2003). Moreover, characteristic of the disorder is an "intolerance of uncertainty" or a tenden- 
cy to hold "beliefs about the necessity of being certain" (Obsessive Compulsive Cognitions Working Group 1997, p. 678).

Jeff Bell offers one of the most comprehensive reports of living with obsessive-compulsive disorder in Rewind, Replay, Repeat (Bell 2006). Unresolvable doubting is one of the major themes of the anecdotes recounted in this memoir. In this passage, Bell recalls a childhood memory of the day in which, after hearing a boy call his name from the seat of a passing car, he is absorbed in an endless enquiry:

this particular night, and I am passing its long hours deep beneath my covers, trying to make sense of the pictures I keep looking through my mind [...] Over and over again, I am replaying these sequences [...] I am doing all this because I have no choice. Two days have come and gone since the scene with the passing car played out for real, and I have filled them with every possible effort to determine just who was trying to get my attention, and why. I'm left with no viable option but to try to re-create for myself the ten or so seconds that hold all my answers (Bell 2006, p. 3).

As Bell's testimony shows, if doubt is generally beneficial with regard to truth-seeking, persistent doubt can paralyze an individual, leaving him unable to reach decisions. When is doubt a valuable epistemic process, and when does it start to hinder one's epistemic pursuits?

If the experience of doubt is central to OCD, we need to be able to define what makes this doubt pathological. When is doubt considered reasonable?

It has been proposed that doubt might be best conceived as an emotional reaction. I will first introduce this view, and then argue that doubt might be best captured as a form of "epistemic anxiety". The view of doubt as an emotion can be seen as having already featured in the works from James and Peirce. James indeed famously remarked:

In its inner nature, belief or the sense of reality, is a sort of feeling more allied to the emotions than anything else [...] The true opposite of belief, psychologically considered, are doubt and inquiry, not disbelief. In both these states the content of our mind is in unrest, and the emotion engendered thereby is, like the emotion of belief itself, perfectly distinct, but perfectly indescribable in words. Both sorts of emotion may be pathologically exalted (James 1890, pp. 283-284).

James hence considered that doubt was best conceived as an emotion, and that there could be instances of pathological doubt. In a similar way, Charles Pierce offered a criticism of Descartes's methodological doubt, arguing that

the mere putting of a proposition into the interrogative form does not stimulate the mind to any struggle after belief. There must be a real and living doubt, and without this all discussion is idle [...] When doubt ceases, mental action on the subject comes to an end (Pierce 1877, p. iv). 
In Peirce's view, the only kind of doubt which we need to take seriously is the one which truly presents a proposition as demanding our attention. Pierce identifies as "real doubt" the doubt which involves some question or problem becoming salient and being literally pressed upon us.

Hookway $(1998,2008)$ proposes that doubt à la Pierce is a form of epistemic anxiety; an anxiety directed at a proposition the truth-value of which we are coming to question. Doubt consists in an evaluative stance in which a proposition's epistemic grounding is deemed uncertain, where this motivates us to reassess its credentials. Hence, doubt might be the form that anxiety takes when it acts as a signal that a proposition we are considering is epistemically uncertain, where this could be problematic for us (given its practical implications). As Hookway (1998, pp. 221-222) suggests: “our awareness that a proposition is poorly supported may receive its primary manifestation in a state of doubt or of epistemic anxiety".

However, while epistemic anxiety seems to always imply doubt, one can doubt something without being epistemically anxious. Pierce opposed "real doubts" to "paper doubts" or theoretical doubts, which merely involve the putting of a proposition into the interrogative form and are not accompanied by a specific phenomenology or a stimulation of the mind. Theoretical or "paper" doubt probably does not involve anxiety. However, theoretical doubt also lacks the kind of salience which truly presents a proposition as demanding our immediate and focused attention. It is only the "real" doubt - the one that is underscored by an affective state - which seems to exert a directive power over attention (Pierce 1877; Hookway 1998).

In other words, doubt can be assimilated to a form of epistemic anxiety when it "is not merely a matter of belief or disbelief, but [...] an irritation that causes inquiry" (Thagard 2006, p. 159). Real doubt is tied with affective states of irritation, excitement and surprise, and implies a struggle after belief. It is a psychological state which contains both an epistemic evaluation and a reason for action. As Hookway (2008, p. 62) suggests: "real doubts motivate me to collect more evidence, to reflect upon the credentials of the erstwhile belief, to worry about other beliefs which depend upon this one and so on".

If "real" doubt is essentially a form of epistemic anxiety, then doubt might be deemed appropriate only if the anxiety that underscores it can be considered an appropriate emotional reaction. If anxiety is inappropriately elicited, it might translate into a maladaptive motivational tendency on the part of the subject to engage in inquiry and sustained search for evidence.

Unreasonable doubt (like in the case of OCD) might involve a dysfunctional disposition with regard to the emotion which underscores this epistemic attitude: anxiety. In what follows, I expose in more detail the mechanisms through which epistemic anxiety motivates sustained epistemic behaviors. 


\section{Elevated Evidence Requirements}

Anxiety, as we have previously defined it, is an emotional state in which a situation, an object, or a proposition is evaluated as problematically uncertain. Since anxiety contains an element of uncertainty, one of the action tendencies of this emotion consists in attempts to acquire knowledge. The question is: how much evidence should one gather before one can claim with confidence that all chances of potential harm have been prevented? When it comes to safety, epistemic certainty does not seem to be within reach. Nonetheless, it would be reasonable for one to be motivated to ensure the highest possible epistemic status.

In the psychology literature, the concept of "elevated evidence requirements" has been discussed as an important maintaining factor in chronic worry (Tallis, Eysenck, Mathews 1991). ${ }^{7}$ As Tallis (1992, p. 22) claims, "a worrier has to be absolutely sure that he or she is doing 'the right thing' before a decision can be made". The authors suggest that "worriers" must consequently spend more time weighting up the relevant information in memory and in the environment.

Several studies have highlighted the tendency of individuals with OCD to gather more evidence, take more time to perform tasks and demand more information to arrive at a decision than comparison groups (Stern et al. 2013; Banca et al. 2015; Fear, Healy 1997; Milner, Beech, Walker 1971). Persons with OCD display "elevated evidence requirements": they experience the need to secure a higher level of evidence before they can resolve an ambiguity, reach a decision and claim knowledge. While they appear to be in possession of sufficient evidence that the stove is off, they seem to fail to achieve psychological certainty with regard to those propositions which obsessive thoughts represent as bearing potential catastrophic implications.

In OCD, we can often distinctly identify two thought components to the doubt: the primary inference of doubt, and the consequences or the secondary inference (O'Connor, Ardema, Pélissier 2005, p. 115). An obsession might for instance start with the thought: "maybe the stove is on", and it might be followed by: "the house will catch fire, I'll lose everything". Where a proposition $p$ ("the stove is on") is appraised as problematic in

${ }^{7}$ What is here identified as worry? Borkovec, Robinson, Pruzinsky and DePree (1983, p. 9) suggest that "worry is a chain of thoughts and images, negatively affect-laden and relatively uncontrollable. The worry process represents an attempt to engage in mental problem-solving on an issue whose outcome is uncertain but contains the possibility of one or more negative outcomes. Consequently, worry relates closely to fear processes". The primary function of worry on this view is to allow individuals to plan options and review possibilities in threatening situations. On this account, worry looks very much like anxiety as we have defined it here. 
view of the potential catastrophic scenarios ("the house will catch fire, I'll lose everything") which could materialize if $p$ turned out to be true, knowing for sure that non- $p$ quickly becomes a question of life or death.

In epistemology, a number of writers have defended the view that knowledge and other epistemic states are not purely epistemic, but also depend upon factors which are of a practical nature. In Knowledge and Practical Interests (2005), Jason Stanley argues that what is at stake for an individual in securing a piece of knowledge can make it more or less justifiable for him to look for further evidence supporting the proposition in question. In his view, the more important the perceived practical interests at stake in resolving $p$, the harder we will find it to have knowledge that $p$ (Stanley 2005). OCD seems to be characterized by a difficulty for subjects to secure knowledge, and a consequent tendency to continue their search and evidence collection.

Patients with OCD are aware that their worries are irrational and their precautions excessive, but do not seem to be able to give up on their attempts to achieve certainty with regard to the propositions they obsess about. In the following section, I will hypothesize that epistemic anxiety is linked to the misplaced tendency to perceive stakes as high and consequently continue the search for information.

\section{Epistemic Anxiety and Stakes}

What does epistemic anxiety have to do with the way in which we represent the practical interests at stake in resolving $p$ as high? Earlier, we have emphasized the idea that emotions impact the regulation of our cognitive activities in a way that serves our practical interests. They act as a source of salience among potential objects of attention and exert a directive power over our cognitive processes (de Sousa 1979; Damasio 1994). In particular, emotions can guide us in deciding whether to stop or continue information search, by quickly representing relevant practical factors. In what follows, I will argue with Nagel (2010) that anxiety can be understood as a mechanism which makes "problematically uncertain" questions salient, and signals the corresponding need for a higher level of required evidence. In representing certain questions as high-stakes, anxiety motivates us to invest a larger amount of cognitive resources in their resolution. While this most often results in an adaptive tendency to invest more cognitive effort in the resolution of high-stakes questions, I will hypothesize that anxiety might be dysfunctional in OCD, misrepresenting stakes and motivating inquiry in a way which does not serve the agent's practical interests.

The emotion of epistemic anxiety has been associated with a motivational tendency to invest greater cognitive efforts and collect more evidence 
in contexts that are evaluated as bearing important consequences for the agent. Jennifer Nagel (2010, p. 9) proposes that "epistemic anxiety", is "a generic expression for the heightened need for greater evidence and more thorough processing that is characteristic of high-stakes situations". As Nagel suggests, epistemic anxiety acts as a signal that the resolution of $p$ will require significant evidence and cognitive processing, given its practical implications. As a result, we will generally invest more cognitive resources into high-stakes questions. As Nagel remarks, a mechanism which makes us invest more effort in belief formation in high stakes circumstances is an adaptive mechanism: "In general, automatic variations in epistemic anxiety makes our thinking more 'adaptive' so that epistemic behavior like evidence-collecting is governed in ways that tend to complement rather than hinder our other pursuits" (Nagel 2010, p. 2).

If this is correct, then we have an emotion which helps us represent the importance of resolving $p$, and quickly identify the questions which are worth extra cognitive effort. While allocating more cognitive effort to a question generally leads to greater accuracy, human cognitive resources are limited, which is why we need to be able to strike a balance between accuracy and speed in belief-formation. However, striking this compromise requires us to be able to quickly and reliably gauge the threshold of evidence that a given question should require, given the practical interests at stake in its resolution.

Indeed, we can only imagine the trouble we would be in, if we had to explicitly deliberate about selecting the right strategy regarding the level of energy to invest on each given question, and the stopping rule to impose on evidence collection. As Nagel remarks, "wondering about finding the right moment to close off inquiry and claim knowledge, one may feel haunted by Sextus Empiricus's suggestion that it is always possible to continue the search" (Nagel 2010, p. 1). The disposition to experience anxiety about whether $p$ might thus be a precious tool to have in our adaptive toolbox, if we are to engage in cognitive activities that are adaptive, given the context, resources and limitations of human cognition.

This being said, if epistemic anxiety is part of a natural and adaptive aspect of the regulation of our cognitive activities, when the emotion is dysfunctional and does not reliably represent the practical stakes, the subject might feel the need to increase cognitive processing and elevate evidence requirements where this is irrelevant. I hypothesize that dysfunctional epistemic anxiety might have an important role to play in the motivation driving persons with OCD to deploy huge cognitive resources for the resolution of apparently simple and innocuous questions. In the case of OCD, epistemic anxiety might be inappropriately elicited, representing these as high-stakes questions, and signaling a need for cognition. This might be particularly 
relevant to patients with checking symptoms, who are overwhelmed by a pressing and recurrent need for verification.

Where epistemic anxiety is dysfunctional, it is likely that we will find ourselves deprived of a helpful guide in our epistemic pursuits.

\section{Conclusion}

I have argued that epistemic anxiety can be a precious tool of our adaptive toolbox and a guide of our epistemic activities. I also suggested that, when ill-calibrated, it is likely to result in maladaptive epistemic pursuits. OCD might be considered an extreme - and indeed a pathological - example of this.

A more general conclusion one might draw from this discussion, is that both an excessive disposition towards epistemic anxiety, and an insufficient one can prove detrimental to an individual's attempts to form beliefs efficiently. Both the "careless" and the "obsessive" are unable to feel appropriate anxiety (or reasonable doubt) and, as a consequence, to allocate cognitive resources where and when it matters. The careless person will overlook important details and her social, moral and epistemic mistakes will remain unnoticed to her. The obsessive agent will engage in endless deliberation, and experience difficulty achieving closure and making decisions.

However, in human affairs, we cannot always afford to wait until we achieve certainty before making a decision. Ecological and practical rationality demand the ability to correctly allocate our cognitive resources, adjusting our epistemic goals to "real-world requirements". This ability might in large part be supported by emotions like epistemic anxiety, which act as precious tools in the guidance of our epistemic activities. ${ }^{8}$

Institut Jean Nicod, Département d'études cognitives ENS, EHESS, PSL University Swiss Center for Affective Sciences, University of Geneva E-mail: juliette.vazard@etu.unige.ch

${ }^{8}$ I wish to thank Fabrice Teroni, Jérôme Dokic, Charlie Kurth, the audience of the Cognitive Irrationality research seminar in Basel and of the Thumos research seminar in Geneva, as well as two anonymous reviewers for their helpful feedback and suggestions. This research was supported by the LabEx IEC research grant ANR-10-LABX-0087 IEC and the IDEX PSL research grant ANR-10-IDEX-0001-02 PSL, and by an Excellence Scholarship from the Swiss Government for foreign scholars. 


\section{References}

Abramowitz, J.S., McKay, D., Taylor, S. (eds.). 2008: Clinical handbook of obsessive-compulsive disorder and related problem, Baltimore, MD, JHU Press.

American Psychiatric Association 1994: Diagnostic and Statistical Manual of Mental Disorders, $4^{\text {th }}$ ed., Washington, DC, American Psychiatric Association.

American Psychiatric Association 2013: Diagnostic and statistical manual of mental disorders, $5^{\text {th }}$ ed., Washington, DC, American Psychiatric Association.

Annas, J. 1993: The morality of happiness, Oxford, Oxford University Press.

Annas, J. 2011: Intelligent virtue, Oxford, Oxford University Press.

Arango-Muñoz, S., Michaelian, K. 2014: "Epistemic Feelings and Epistemic Emotions", Focus Section, Philosophical Inquiries, 2 (1), pp. 97-122.

Attiullah, N., Eisen, J.L., Rasmussen, S.A. 2000: "Clinical features of obsessivecompulsive disorder”, Psychiatric Clinics, 23 (3), pp. 469-491.

Banca, P., Vestergaard, M.D., Rankov, V., Baek, K., Mitchell, S., Lapa, T., Voon, V. 2015: "Evidence accumulation in obsessive-compulsive disorder: the role of uncertainty and monetary reward on perceptual decision-making thresholds", Neuropsychopharmacology, 40 (5), pp. 1192-1202.

Barlow, D. 2001: Anxiety and its disorders, $2^{\text {nd }}$ ed., New York, Guilford Press.

Bell, J. 2010: Rewind Replay Repeat: A Memoir of Obsessive Compulsive Disorder, New York, Simon and Schuster.

Bolton, D., Hill, J. 1996: Mind, meaning, and mental disorder: The nature of causal explanation in psychology and psychiatry, Oxford, Oxford University Press.

Brady, M.S. 2013: Emotional insight: The epistemic role of emotional experience, Oxford, Oxford University Press.

Brun, G., Doğuoğlu, U., Kuenzle, D. (eds.) 2008: Epistemology and emotions, Aldershot-Burlington, Ashgate Publishing Ltd.

Damasio, A.R. 1994: Descartes' error: Emotion, rationality and the human brain, New York, Avon Books.

Deonna, J., Teroni, F. 2012: The emotions: A philosophical introduction, London-New York, Routledge.

De Sousa, R. 1979: "The rationality of emotions", Dialogue: Canadian Philosophical Review/Revue canadienne de philosophie, 18 (1), pp. 41-63.

De Sousa, R. 1987: The Rationality of. Emotion, Cambridge, MA, MIT Press.

De Sousa, R. 2009: "Epistemic feelings", Mind and Matter, 7 (2), pp. 139-161.

Diniz, J.B., Miguel, E.C., de Oliveira, A.R., Reimer, A.E., Brandão, M.L., de Mathis, M.A., Batistuzzo, M.C., Costa, D.L.C., Hoexter, M.Q. 2012: "Outlining new frontiers for the comprehension of obsessive-compulsive disorder: a review of its relationship with fear and anxiety", Revista Brasileira de Psiquiatria, 34, pp. 84-103. 
Dokic, J. 2012: "Seeds of self-knowledge: noetic feelings and metacognition", in M.J. Beran, J. Brandl, J. Perner, J. Proust (eds.), Foundations of metacognition, Oxford, Oxford University Press, pp. 302-321.

Fear, C.F., Healy, D. 1997: "Probabilistic reasoning in obsessive-compulsive and delusional disorders", Psychological medicine, 27 (1), pp. 199-208.

Frost, R.O., Steketee, G., Cohn, L., Griess, K. 1994: "Personality traits in subclinical and non-obsessive-compulsive volunteers and their parents", Behaviour Research and Therapy, 32 (1), pp. 47-56.

Gerken, M. 2017: On folk epistemology: How we think and talk about knowledge, Oxford, Oxford University Press.

Gigerenzer, G. 2008: Rationality for mortals: How people cope with uncertainty, Oxford, Oxford University Press.

Gigerenzer, G., Todd, P.M. 1999: "Fast and frugal heuristics: The adaptive toolbox", in G. Gigerenzer, P.M. Todd, ABC Research Group, Simple heuristics that make us smart, Oxford, Oxford University Press, pp. 3-34.

Hoehn-Saric, R., McLeod, D.R. 2000: "Anxiety and arousal: physiological changes and their perception", Journal of affective disorders, 61 (3), pp. 217-224.

Hookway, C. 1998: "Doubt: Affective states and the regulation of inquiry", Canadian Journal of Philosophy, 28, pp. 203-225.

Hookway, C. 2008: "Epistemic immediacy, doubt and anxiety: On a role for affective states in epistemic evaluation", in Brun, Doğuoğlu, Kuenzle (eds.) 2008, pp. 51-65.

Hursthouse, R. 1999: On virtue ethics, Oxford, Oxford University Press.

Janet P. 1919: Les Obsessions et la Psychasthenie, $3^{\text {rd }}$ ed., Paris, Alcan.

Kant, I. 1797/1996: "Metaphysics of morals", in Id., Practical philosophy, ed. By M. Gregor and A. Wood, Cambridge, Cambridge University Press, pp. 353-604.

Kashdan, T.B., Silvia, P.J. 2009: "Curiosity and interest: The benefits of thriving on novelty and challenge", Oxford handbook of positive psychology, 2, pp. 367-374.

Kruglanski, A.W. 1990: "Lay epistemic theory in social-cognitive psychology", Psychological Inquiry, 1 (3), pp. 181-197.

Kurth, C. 2015: "Moral anxiety and moral agency", in M. Timmons (ed.), Oxford Studies in Normative Ethics, vol. 5, Oxford, Oxford University Press, pp. 171-195.

Litman, J. 2005: "Curiosity and the pleasures of learning: Wanting and liking new information”, Cognition \& emotion, 19 (6), pp. 793-814.

Mayseless, O., Kruglanski, A.W. 1987: "What makes you so sure? Effects of epistemic motivations on judgmental confidence", Organizational Behavior and Human Decision Processes, 39 (2), pp. 162-183.

McDowell, J. 1998: Mind, value, and reality, Cambridge, MA, Harvard University Press. 
Meylan, A. 2014: “Epistemic Emotions: a Natural Kind?”, Philosophical Inquiries, 2 (1), pp. 173-190.

Milner, A.D., Beech, H.R., Walker, V.J. 1971: "Decision processes and obsessional behaviour", British Journal of Clinical Psychology, 10 (1), pp. 88-89.

Morton, A. 2010: "Epistemic emotions", in P. Goldie (ed.), The Oxford Handbook of Philosophy of Emotion, Oxford, Oxford University Press, pp. 385-399.

Nagel, J. 2010: "Epistemic anxiety and adaptive invariantism", Philosophical Perspectives, 24 (1), pp. 407-435.

Obsessive Compulsive Cognitions Working Group 1997: "Cognitive assessment of obsessive-compulsive disorder", Behaviour Research and Therapy, 35, pp. 667-681.

O'Connor, K., Aardema, F., Pélissier, M.C. 2005: Beyond reasonable doubt: Reasoning processes in obsessive-compulsive disorder and related disorders, Chichester, John Wiley \& Sons.

Öhman, A. 1993: "Fear and anxiety as emotional phenomena: Clinical phenomenology, evolutionary perspectives, and information-processing mechanisms", in M. Lewis, J.M. Haviland (eds.), Handbook of emotions, New York, Guilford Press, pp. 511-536.

Peirce, C.S. 1877: "The fixation of belief", Popular Science Monthly, 12 (1), pp. $1-15$.

Price, C. 2006: "Affect without object: moods and objectless emotions", European journal of analytic philosophy, 2 (1), pp. 49-68.

Rachman, S., de Silva, P. 1978: "Abnormal and normal obsessions", Behaviour research and therapy, 16 (4), pp. 233-248.

Rachman, S. 1993: "Obsessions, responsibility and guilt", Behaviour research and therapy, 31 (2), pp. 149-154.

Rachman, S. 2003: The treatment of obsessions, Oxford, Oxford University Press.

Reed, G.F. 1985: Obsessional experience and compulsive behaviour: A cognitivestructural approach, London, Academic Press.

Roets, A., Kruglanski, A.W., Kossowska, M., Pierro, A., Hong, Y.Y. 2015: "The motivated gatekeeper of our minds: New directions in need for closure theory and research", Advances in experimental social psychology, 52, 221-283.

Rorty, A. (ed.) 1980: Explaining emotions, Berkeley, University of California Press.

Salkovskis, P.M. 1985: "Obsessional-compulsive problems: A cognitivebehavioural analysis", Behaviour Research and Therapy, 23 (5), pp. 571-583.

Salkovskis, P.M. 1999: "Understanding and treating obsessive-compulsive disorder", Behaviour Research and Therapy, 37, pp. 29-52.

Salkovskis, P.M., Harrison, J. 1984: "Abnormal and normal obsessions - a replication”, Behaviour Research and Therapy, 22 (5), pp. 549-552.

Shafran, R., Watkins, E., Charman, T. 1996: "Guilt in obsessive-compulsive disorder”, Journal of Anxiety Disorders, 10 (6), pp. 509-516. 
Shapiro, D. 1965: Neurotic styles, New York, Basic Books.

Stanley, J. 2005: Knowledge and practical interests, Oxford, Clarendon Press.

Stern, E.R., Welsh, R.C., Gonzalez, R., Fitzgerald, K.D., Abelson, J.L., Taylor, S.F. 2013: "Subjective uncertainty and limbic hyperactivation in obsessive-compulsive disorder", Human brain mapping, 34 (8), pp. 1956-1970.

Szechtman, H., Woody, E. 2004: "Obsessive-compulsive disorder as a disturbance of security motivation", Psychological review, 111 (1), pp. 111-127.

Tallis, F., Eysenck, M., Mathews, A. 1991: "Elevated evidence requirements and worry", Personality and Individual Differences, 12 (1), pp. 21-27.

Tallis, F., Eysenck, M., Mathews, A. 1992: "A questionnaire for the measurement of nonpathological worry", Personality and Individual Differences, 13 (2), pp. 161-168.

Thagard, P. 2006: Hot thought: Mechanisms and Applications of Emotional Cognition, Cambridge, MA, MIT Press.

Tolin, D.F., Abramowitz, J.S., Brigidi, B.D., Foa, E.B. 2003: "Intolerance of uncertainty in obsessive-compulsive disorder", Journal of Anxiety Disorders, 17 (2), pp. 233-242.

Wilkins, J. 1675: Principles and Duties of Natural Religion, London, Basset, Brome, and Chiswell. 